\title{
Comparative Study on the Marginal Strengths of Conventional and Spherical Amalgam Alloys
}

\section{- Invention of a Device for the Measurement} of Marginal Strength -

\author{
by
}

Kazuo NAGAI, Masayoshi OHASHI and Kiyoshi HASEGAWA

\section{Research Collaborators}

T. Shimizu, M. Uemura, K. Mihara, T. Shimojo, M. Toriumi and T. Ozaki

1. Introduction

2. Materials and Method

2.1 Materials

2.2 Preparation method of test specimens

2.3 Measurement device and method

3. Preliminary Experiments

3.1 Marginal fracture owing to differences in means and time of trituration

3.2 Marginal fracture owing to different surfaces on which load is placed

4. Experimental Results

4.1 Influence of angles on marginal strength

4.2 Changes in marginal strength to the time passage

5. Discussions

5.1 Consideration of experimental method

5.2 Consideration of experimental results

5.2.1 Influences of angles on marginal strength

5.2.2 Changes in marginal strength to the time passege

6. Conclusions

\section{Introduction}

Despite the general knowledge that more than $75 \%$ of dental restorations are made by amalgam fillings at present [1], there have been reported many cases of failure in amalgam restorations by various investigators: HeAley and Phillips [2], SEINo [3], FusAyama et al. [4], SAijo[5], Habu et al. [6], and Wilson and Ryge[7] among

永井一夫, 大橋 正敬, 長谷川 清: Department of Dental Materials, Nihon Univ. School of Dentistry, Tokyo. 
others. The main cause for these failures is attributed to an inadequate cavity preparation by a dentist and unsatistactory manipulation of amalgam material. But the authors have been long of the opinion that a major cause should be sought rather in the material deficiency inherent in amalgam itself.

A development of new amalgam made from spherical particle alloy by FederalMogul-Bower Bearings, Inc., Detroit, Michigan, U. S. A. in 1961 created a great epoch in the history of dental amalgam extending for 100 years, being awarded U.S. Patent No. 2,968,062 for their new manufacturing apparatus [8].

Partial reports dealing with this atomized spherical-particle amalgam alloy were published in succession by Demaree and TAYLOR [9] in 1962, KORAN and AsGAR [10] in 1965, EDEN and Waterstrat [11], Wing and Ryge [12] and Kamata [13]. In 1966, NAGAI, OHASHI and MiYAZU with the collaboration of many investigators [14] carried out extensive studies on spherical amalgam that was successfully developed for a commercial market for the first time in the world.

These studies included research efforts from a dental technological point of view as well as clinical standpoint, such as: 1) Influence of alloy-to-mercury ratio and condensation pressure on compressive strength, 2) Chronological changes in compressive strength, 3) Pre-setting flow analysis of filling material, 4) Influence of the plugger diameter on compressive strength, 5) Hardness tests, 6) Flow tests, 7) Dimensional changes, 8) Corrosive resitancy tests by the polarography and 9) Semi-clinical investigation of amalgam fillings. These findings have been published both in Japanese and English for the benefit of clinicians and investigators in the same field.

In the early part of 1967, NAGAI and OHASHI [15] published a comparative study between spherical and conventional amalgams concerning their respective dimensional changes under various conditions. They also succeeded in developing a new-NON condensing apparatus for the preparation of test specimens in amalgam specification test [16]. By test specimens prepared by this new apparatus, respective compressive strengths of spherical and conventional amalgams were measured and the excellent properties of spherical amalgam were established in consequence.

A large percentage of amalgam filling failures as mentioned above is due to the fracture of their margins, i. e., the weakness in marginal portion of amalgam fillings is responsible for these failures. Untill 1965 when J $\phi$ RGENSEN of Denmark developed a new apparatus in an effort to elucidate the marginal strength of conventional amalgams, efforts had been merely made to determine the marginal strength by inference from compressive strength $[17,18]$. The present report is concerned with a comparison of marginal strengths on the part of spherical and conventional amalgams by modifying the method devised by J $\phi$ RGENSEN, for the purpose of making clear the marginal strength of dental amalgam for the benefit of clinicians.

\section{Materials and Method}

\subsection{Materials}

As indicated in Table 1 below, for study purposes use was made of Shofu Spherical Amalgam (Lot No. 17) and for comparison as conventional amalgam 2 domestic products of Micro Non-zinc Amalgam (Shofu, Lot No. 41), Luna Amalgam (G-C Chemical, Lot No. R0-7) and 2 foreign products of New True Dentalloy (S. S. White, Lot No. 16863277) and Micro Non-zinc Amalgam (Caulk, Lot No. 7G-65) were selected 
TABLE 1

Amalgam alloys tested

\begin{tabular}{c|c|c|c}
\hline \hline Abbreviation & Brand of name & Batch no. & Manufacturer \\
\cline { 2 - 3 } S & Spherical (non-zinc) & 17 & Shofu, Japan \\
M & Micro (non-zinc) & 41 & Shofu, Japan \\
L & Luna & RO 7 & G. C, Japan \\
T & New True Dentalloy & 16863277 & S. S. White, U. S. A. \\
C & Micro (non-zinc) & $7 G 65$ & Caulk, U. S. A.
\end{tabular}

from among those in wide use.

\subsection{Preparation method of test specimens.}

Fig. 1 give metal molds and retaining devices used for the preparation of test specimens from spherical and 4 different conventional amalgams as listed in the preceding section.

Alloy-to-mercury ratios were observed as specified by the manufacturers, the materials were weighed by the use of scales having the minute reading of $0.01 \mathrm{~g}$ and they were mechanically triturated in 15 seconds. The mix was packed into mold (Fig. 1-C, Fig. 2), $2 \times 4 \times 30 \mathrm{~mm}$, and the packing was effected by NON condensing apparatus (Fig. 3) [14], under two condensation pressures of $10 \mathrm{~kg} / \mathrm{cm}^{2}$ and $60 \mathrm{~kg} / \mathrm{cm}^{2}$.

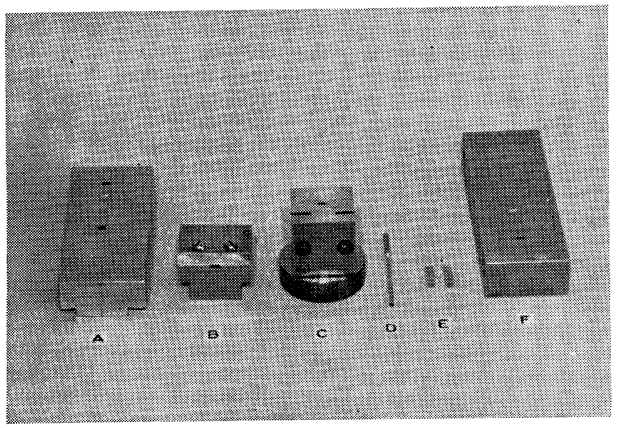

Fig. 1. Molds and holders used for test specimens

A Holder (Fig. 14 for details)

B Holder (Fig. 8 for details)

C Mold for the preparation of test specimens (Fig. 2 for details)

D Condenser $(1.5 \mathrm{~mm} \times 2 \mathrm{~mm})$

E Condenser $(2 \mathrm{~mm} \times 4 \mathrm{~mm})$

F Mold for polishing test specimens (Figs. 4 and 5 for details)

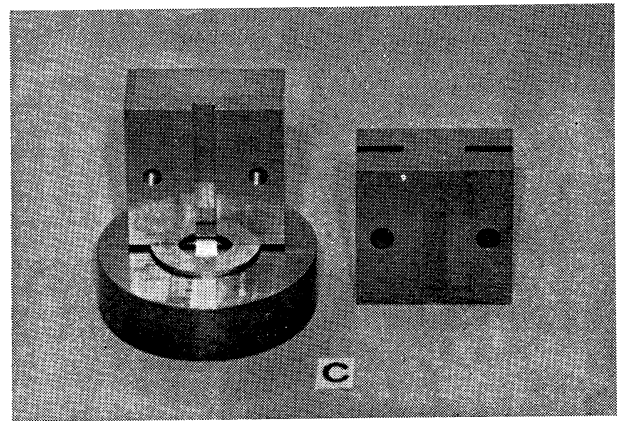

Fig. 2. Metal mold for the preparation of test specimens

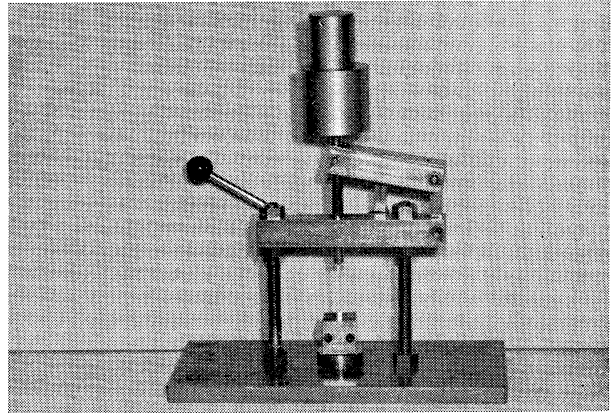

Fig. 3. NON condensing apparatus 
Mechanical triturators used were the Shofu "Spherical amalgam mixer" for spherical and the G-C "Luna IIB" for conventional amalgams. By way of packing, the triturated mix was divided into four equal parts and one part was placed in a metal mold and was subjected to respective pressures of $1.8 \mathrm{~kg}$ and $0.3 \mathrm{~kg}$ (corresponding to $60 \mathrm{~kg} / \mathrm{cm}^{2}$ and $10 \mathrm{~kg} / \mathrm{cm}^{2}$ respectively) by a square condenser of $1.5 \times 2 \mathrm{~mm}$ (Fig. 1-D). When pressure was exerted five times in succession, the position was changed so that pressure was exerted uniformly, thus packing the mix 25 times altogether. The same procedure was applied to the remaining 3 parts and, in consequence, a total of 100 packings was carried out. In the final process, a condenser of $2 \times 4 \mathrm{~mm}$ (Fig. 1-E) was used to apply $4.8 \mathrm{~kg}$ and $0.8 \mathrm{~kg}$ pressures (these corresponding to $60 \mathrm{~kg} /-$ $\mathrm{cm}^{2}$ and $10 \mathrm{~kg} / \mathrm{cm}^{2}$ ) for one minute.

These entire procedures were completed within 4 minutes of the start of trituration. After the final pressure was applied, the specimen was left standing for 3 minutes. Then a sharp razor edge was applied to the top of the specimen to cut it to the length of $15 \mathrm{~mm}$ and it was pushed out the mold. This test specimen thus prepared had dimensions of $2 \times 4 \times 15 \mathrm{~mm}$ and it was immediately stored in a container kept at $37 \pm$ $1^{\circ} \mathrm{C}$. However, the preparation of test specimens and various tests subsequently were conducted at a room temperature of $23 \pm 2^{\circ} \mathrm{C}$.

The amount of mercury which was squeezed out of the specimen at the final application of pressure was measured and it was used to calculate that of residual mercury left in the test specimens. Of course, mercury squeezed could not be said absolutely pure and, for this reason, the residual mercury here was not strictly accurate but this method of calculation was adopted for the sake of convenience, as affording us an indication.

The test specimens that were stroed at a temperature of $37 \pm 1^{\circ} \mathrm{C}$ were taken out on the occasion of each test. They were inserted in special mold (Fig. 1-F, Figs. 4 and 5) to give various angles on the margin. These were polished and carved in association with the use of water to prevent possible heat generation, receiving final finish by the water-proof polishing paper No. 1000. As shown in Fig. 6, these test specimens could be readily and accurately provided with various angles under the uniform conditions by the use of polishing mold. Four different marginal angles were given: $30^{\circ}$,
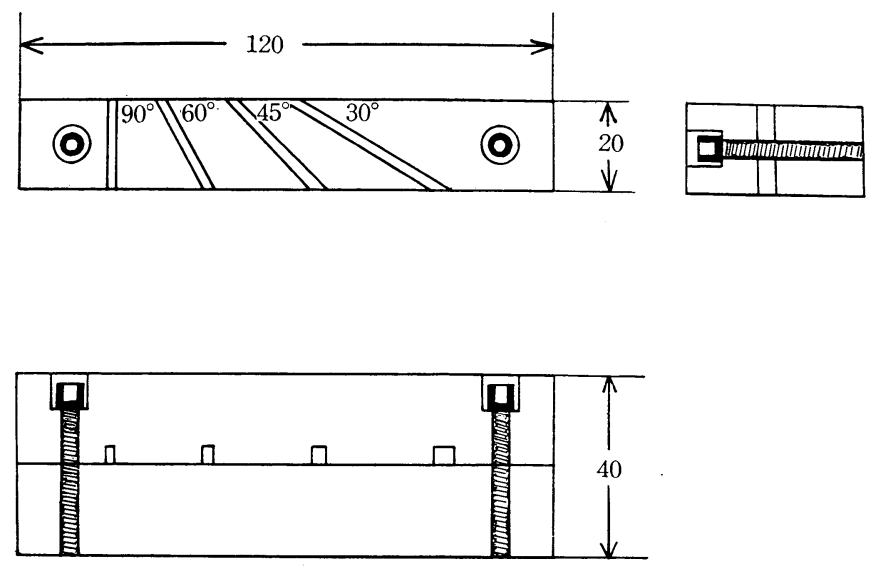

Fig. 4. Metal mold for polishing test specimens 


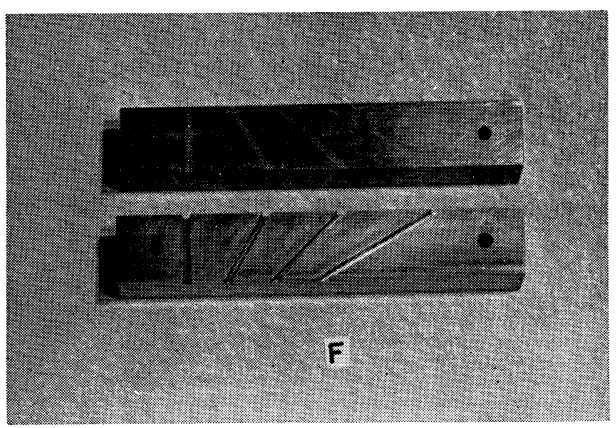

Fig. 5. Metal mold for polishing test specimens

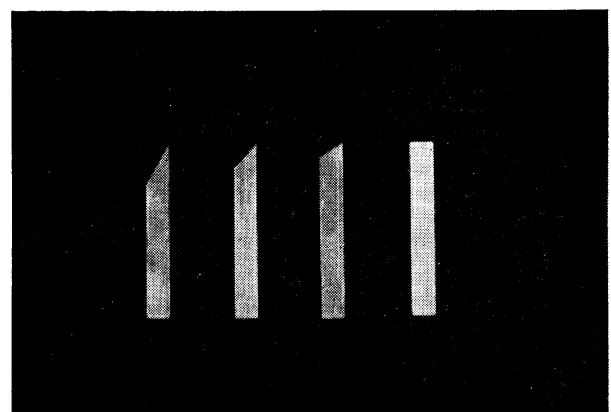

Fig. 6. Test specimens with various marginal angles $\left(30^{\circ}, 45^{\circ}, 60^{\circ}\right.$ and $90^{\circ}$ from left to right)

$45^{\circ}, 60^{\circ}$ and $90^{\circ}$. With all the test specimens, the degree of fracture on the margin was measured after the passage of 24 hours. On the other hand, the test specimens that were given $30^{\circ}$ were differently measured at intervals of $5,10,24$ hours and 7 days, the measurement data being comparatively studied.

In using the experimental data, 10 different measurements were divided to produce arithmetic means as indicating the marginal strength of each specimen tested.

\subsection{Measurement device and method.}

J $\phi$ RGENSEN [18], a well-known Danish investigator of dental materials, used a scratching apparatus in his study on the marginal strength of dental amalgams. The authors used here, however, the Micro Vickers hardness tester (Fig. 7) for the reason that this tester is capable of easy microscopic inspection and measurement of fractured portions. Certain modification was made of the tester to suit our purpose better, so that the retention of test specimens was improved and their dropping distance of load made uniform, where a steel ball of $1.0 \mathrm{~mm}$ in diameter was used in association with $500 \mathrm{~g}$ pressure.

As indicated by Figs. 1-B and 8, the holder was especially designed in order that the test specimens could be securely held in place. The height of $60 \mu$ was chosen as a dropping distance, the purpose being to measure the marginal fracture to be caused by only the tip of $1.0 \mathrm{~mm}$ steel ball dropping on the surface of test specimens (Fig. 9). In the first place, the dial (A) was set to the established height of $60 \mu$ and load part was similarly lifted, the ohm range of an electric tester being used in this state to see whether the electric current was on. While paying attention to the electric tester, we lifted a test specimen by the handle $(\mathbf{B})$ to the height where the tip

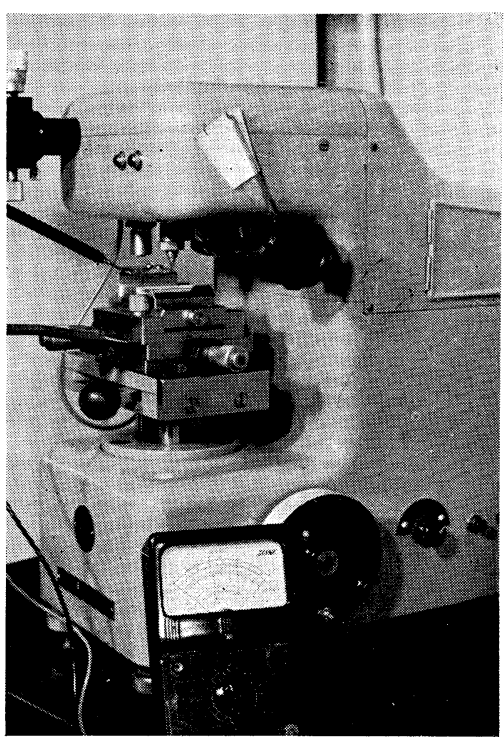

Fig. 7. Micro Vickers Hardness tester 

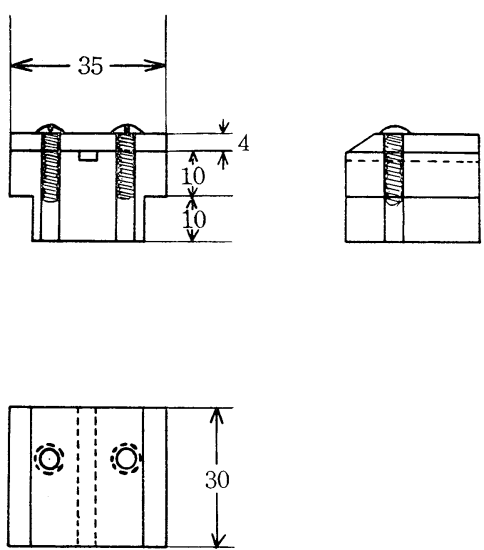

Fig. 8. Sketch of a holder for test specimens

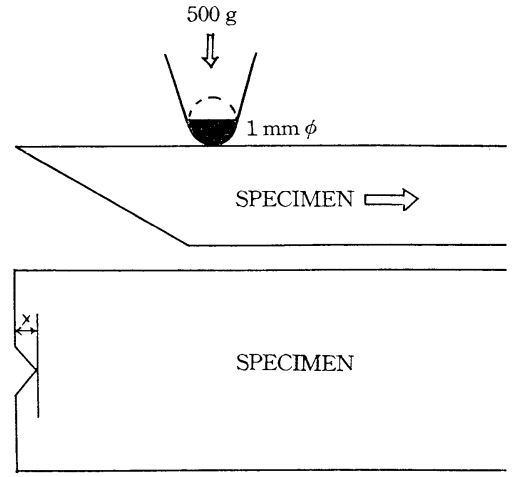

Fig. 10. Method for measuring depth of marginal fracture (J $\phi$ RGENSEN's method)

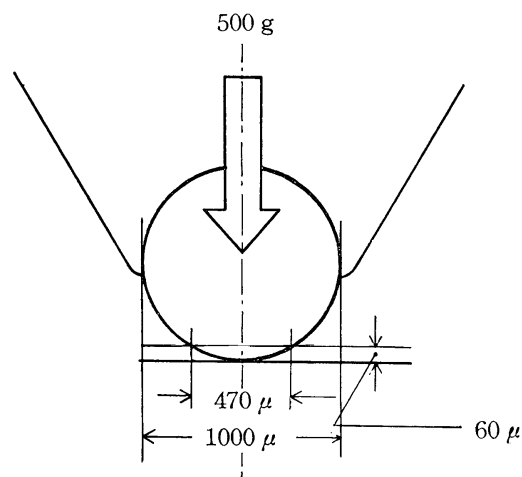

Fig. 12. Tip portion of loading apparatus

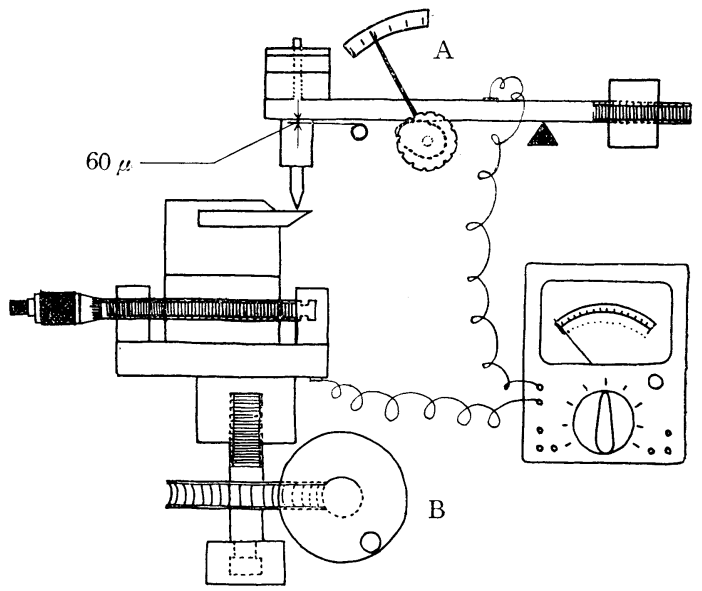

Fig. 9. Schematic presentation of rendering the drop of steel ball to a uniform distance $(60 \mu)$

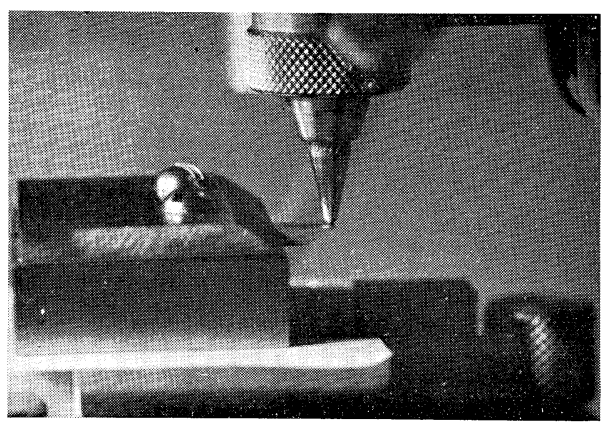

Fig. 11. Condition where load is applied on the margin

of loading part came in contact with its surface. The loading part was activated by the cam from the position of $60 \mu$ so that a load $500 \mathrm{~g}$ was applied to a test specimen through the medium of a steel ball, where the test specimen was horizontally moved at a speed of $50 \mu$ per second and a load was gradually applied toward the margin (Figs. 10 and 11). The movement of test specimen was stopped at the moment when a fracture was developed in its margin; here the load was dropped by $60 \pm 3 \mu$ and a steel ball came to a halt at $470 \mu$ of its $1.0 \mathrm{~mm}$ diameter (Fig. 12). The test specimen thus fractured in the margin was removed to 
an optical microscope of $100 \times$ attached to the Micro Vickers tester for careful examination. By the microscope the $\mathrm{V}$-shaped fracture was measured regarding its depth and it was interpreted as indicative of the marginal strength of a test specimen under consideration. In this method we followed J $\phi$ RGENSEN, as it is recognized that the shorter is the distance of fracture, the stronger the marginal strength of a specimen (Fig. 10).

\section{Preliminary Experiments}

3.1 Marginal fracture owing to differences in means and time of trituration.

It is an established fact that the marginal strength of amalgam is largely influenced by a mixer and its trituration time. For this reason, the following series of preliminary experiments was carried out so as to select a method of trituration.

a. Spherical and conventional amalgams were triturated for 3 seconds by the use of G-C Luna Amalgamator IIB without placing a ball inside the capsule.

b. Spherical and conventional amalgams were triturated for 15 seconds by the use of Shofu Spherical Amalgam Mixer.

c. Spherical and conventional amalgams were triturated for 15 seconds by G-C Luna Amalgamator with a ball inside the capsule.

Conventional amalgam used here was Micro Non-zinc Amalgam, a Shofu product, and effects of trituration were compared with these different methods (Table 2).

TABLE 2

Effect of mixer and trituration time on depth of fracture of amalgams

24 hours, Angle $30^{\circ}$, Temp. $37^{\circ} \mathrm{C}$

\begin{tabular}{|c|c|c|c|}
\hline \multirow[b]{3}{*}{ Amalgam } & 1 & 2 & 3 \\
\hline & $\begin{array}{l}\text { G. C. Luna } \\
\text { Without ball }\end{array}$ & $\begin{array}{c}\text { Shofu } \\
\text { Without ball }\end{array}$ & $\begin{array}{l}\text { G. C. Luna } \\
\text { With Ball }\end{array}$ \\
\hline & $3 \mathrm{sec}$. & $15 \mathrm{sec}$. & $15 \mathrm{sec}$. \\
\hline Spherical & $414(26) \mu$ & 381 (39) $\mu$ & 395 (19) $\mu$ \\
\hline Micro & Can't Mix & 458 (25) & 416 (31) \\
\hline Ratio & $\begin{array}{l}\text { Conde } \\
\text { pressu }\end{array}$ & $\begin{array}{l}10 \mathrm{~kg} / \mathrm{cm}^{2} \\
60 \mathrm{~kg} / \mathrm{cm}^{2}\end{array}$ & \\
\hline
\end{tabular}

Numbers in parentheses are standard deviation.

As is known from Table 2, the first method of 3 -second trituration was found insufficient with a large marginal fracture consequently and when the second and third methods were compared, nearly same result was obtained with a mixer exclusively devoted to spherical amalgam. With reference to conventional amalgam, on the other hand, the first method failed also to obtain an adequate amalgam mixture and a comparison of the second and third methods indicated that a conventional amalgam mixer was quite advantageous. Attention should be drawn to the fact that while conventional amalgam was packed under a high condensation pressure of $60 \mathrm{~kg} / \mathrm{cm}^{2}$, spherical 
amalgam was packed at a pressure as low as $10 \mathrm{~kg} / \mathrm{cm}^{2}$.

From these preliminary experiments, it was decided that spherical amalgam was subjected to 15 seconds trituration by the use of a mixer especially devoted for spherical amalgam and conventional amalgam was similarly to be triturated for 15 seconds by the use of G-C Luna Amalgamator.

3.2 Marginal fracture owing to different surfaces on which load is placed.

In applying load for the investigation of marginal strength of amalgams, we adopted two different methods to be referred to as method-A and method-B (Fig. 13). In method-A a load was applied on the unpolished surface and in method-B, on the

A

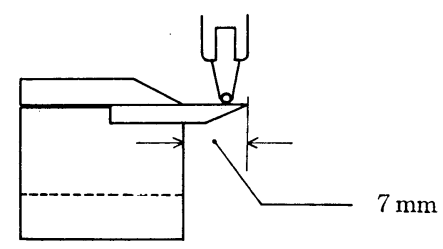

B

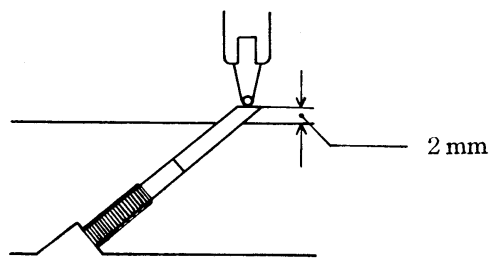

Fig. 13. Specimen holder

A Load applied on the unpolished surface (Fig. 1-B)

B Load applied on the polished surface (Fig. 1-A)

TABLE 3

Comparison of marginal fractures of the unpolished (A) and polished (B) surfaces

$60 \mathrm{~kg} / \mathrm{cm}^{2} 30^{\circ} 37^{\circ} \mathrm{C} 24$ Hours

\begin{tabular}{|c|c|c|}
\hline Amalgam & $A \Longrightarrow$ & $\mathrm{B} / \frac{\downarrow}{7}$ \\
\hline Spherical & $374(10) \mu$ & 377 (17) $\mu$ \\
\hline licro & 416 (31) & $414(26)$ \\
\hline
\end{tabular}

Numbers in parentheses are standard deviation. hours in spherical and 4 different products of conventional amalgam: Shofu Micro Non-zinc Amalgam, G-C Luna Amalgam, S. S. White New True Dentalloy and Caulk Micro Non-zinc Amalgam. As is learned from this comparison, in common with spherical and conventional amalgams when the angle is large the marginal strength will become correspondingly great. Spherical amalgam generally gives greater marginal strength and

other hand, a load was applied on the polished surface of amalgam specimens (Figs. 1-A and 14 illustrate the holder for test specimens), the results of both cases to be comparatively examined.

From a clinical consideration, method$\mathrm{B}$ may strike one to be favorable but, as a matter of fact, there was established no appreciable difference between the two (Table 3). For this reason, in the present study the method-A was adopted for the economy of time.

\section{Experimental Results}

4.1 Influence of angles on marginal strength.

Table 4 indicates influence of different angles on the marginal strengths after 24 
there is found no large difference between pressures of $10 \mathrm{~kg} / \mathrm{cm}^{2}$ and $60 \mathrm{~kg} / \mathrm{cm}^{2}$.

On the other hand, conventional amalgam products have smaller marginal strength

TABLE 4

Effect of marginal angle on depth of fracture of various amalgams

Temp. $37^{\circ} \mathrm{C} \quad 24$ Hours

\begin{tabular}{|c|c|c|c|c|c|}
\hline Name & $\begin{array}{l}\text { Shofu } \\
\text { Spherical }\end{array}$ & $\begin{array}{l}\text { Shofu } \\
\text { Micro }\end{array}$ & $\begin{array}{l}\text { G. C. } \\
\text { Luna }\end{array}$ & $\begin{array}{l}\text { S. S. White } \\
\text { New } \\
\text { True Dent. }\end{array}$ & $\begin{array}{l}\text { Caulk } \\
\text { Micro }\end{array}$ \\
\hline Ratio & $1.0: 0.85$ & $1.0: 1.2$ & $1.0: 1.2$ & $1.0: 1.2$ & $1.0: 1.2$ \\
\hline Angle $\mathrm{kg} / \mathrm{cm}^{2}$ & $10 \quad 60$ & $10 \quad 60$ & $10 \quad 60$ & $10 \quad 60$ & $10 \quad 60$ \\
\hline $30^{\circ}$ & $\begin{array}{l}381 \mu 374 \mu \\
(39) \quad(10)\end{array}$ & $\begin{array}{l}447 \mu 416 \mu \\
(46) \quad(31)\end{array}$ & $\begin{array}{l}417 \mu 411 \mu \\
(13) \quad(8)\end{array}$ & $\begin{array}{l}417 \mu 381 \mu \\
(22) \quad(27)\end{array}$ & $\begin{array}{l}443 \mu 413 \mu \\
(21) \quad(10)\end{array}$ \\
\hline $45^{\circ}$ & $\begin{array}{ll}273 & 254 \\
(20) & (16)\end{array}$ & $\begin{array}{ll}309 & 264 \\
(15) & (\text { I } 3)\end{array}$ & $\begin{array}{ll}291 & 288 \\
(20) & (42)\end{array}$ & $\begin{array}{ll}270 & 252 \\
(27) & (37)\end{array}$ & $\begin{array}{ll}287 & 275 \\
(17) & (19)\end{array}$ \\
\hline $60^{\circ}$ & $\begin{array}{ll}146 & 146 \\
(17) & (13)\end{array}$ & $\begin{array}{ll}191 & 161 \\
(20) & (22)\end{array}$ & $\begin{array}{ll}195 & 170 \\
(16) & (32)\end{array}$ & $\begin{array}{ll}194 & 165 \\
(44) & (35)\end{array}$ & $\begin{array}{ll}197 & 179 \\
(51) & (23)\end{array}$ \\
\hline $90^{\circ}$ & $\begin{array}{cc}56 & 51 \\
(6) & (8)\end{array}$ & $\begin{array}{cc}74 & 54 \\
(22) & (17)\end{array}$ & $\begin{array}{cc}62 & 59 \\
(10) & (3)\end{array}$ & $\begin{array}{ll}84 & 62 \\
(8) & (8)\end{array}$ & $\begin{array}{rr}62 & 57 \\
(11) & (6)\end{array}$ \\
\hline
\end{tabular}

Numbers in parentheses are standard deviation.

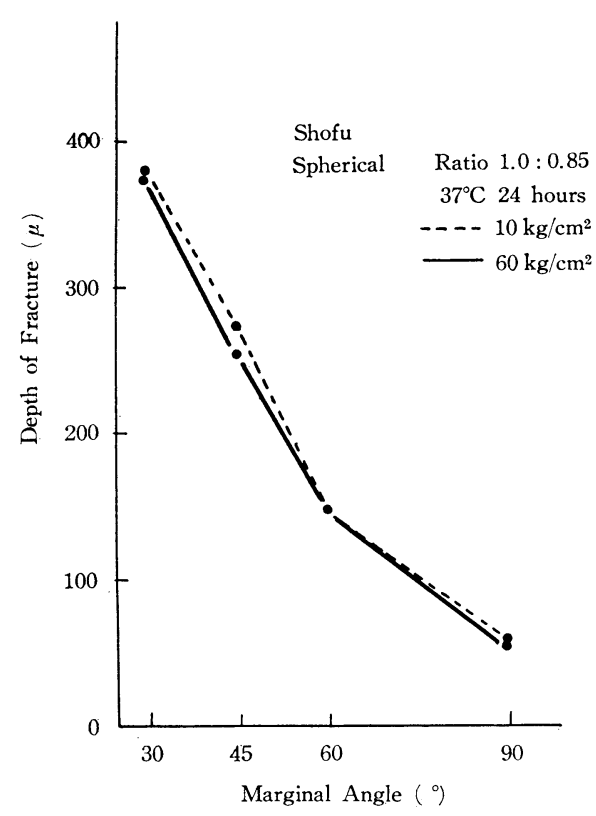

Fig. 15. Effect of marginal angle on depth of fracture of amalgam

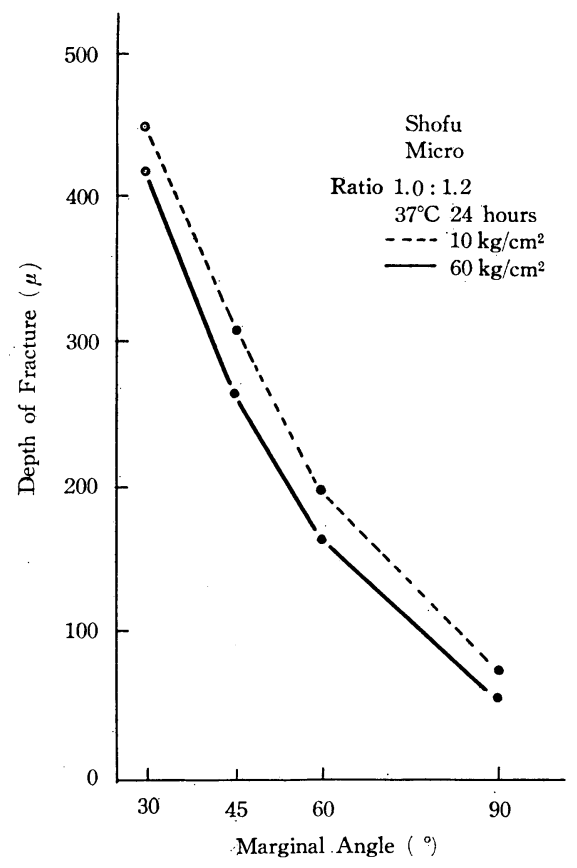

Fig. 16. Effect of marginal angle on depth of fracture of amalgam 


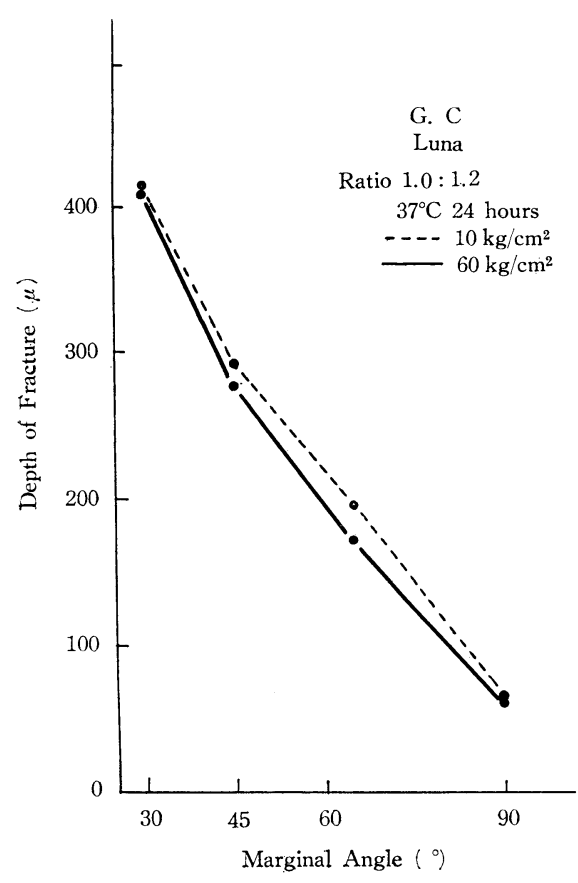

Fig. 17. Effect of marginal angle on depth of fracture of amalgam

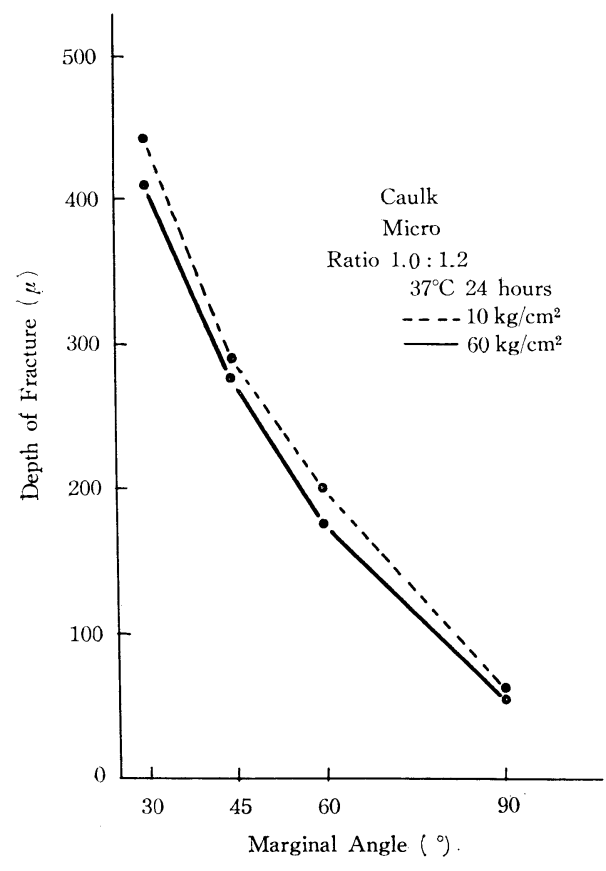

Fig. 19. Effect of marginal angle on depth of fracture of amalgam

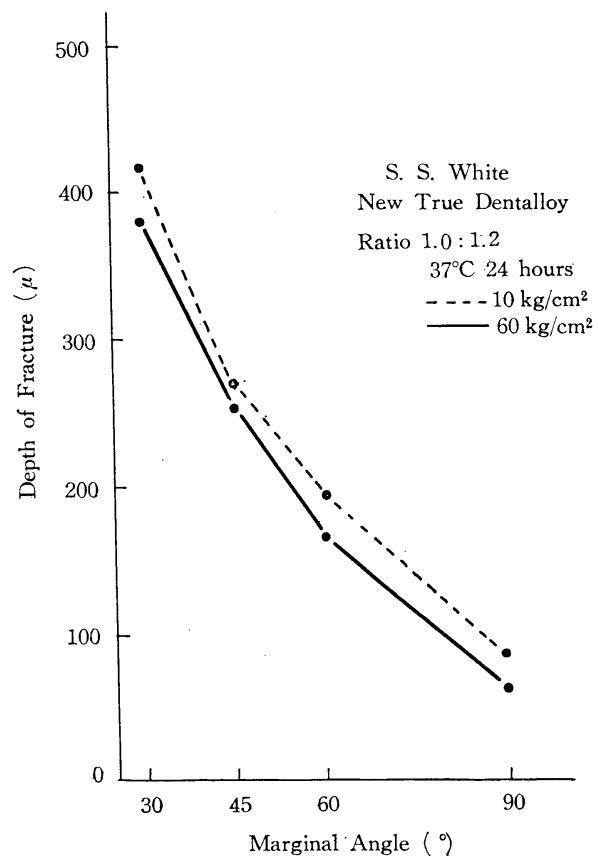

Fig. 18. Effect of marginal angle on depth of fracture of amalgam

and a large difference exists between 10 $\mathrm{kg} / \mathrm{cm}^{2}$ and $60 \mathrm{~kg} / \mathrm{cm}^{2}$ condensation pressures. Fig. 15 gives changes in marginal strength attendant upon changes in angles with spherical amalgam packed under 10 $\mathrm{kg} / \mathrm{cm}^{2}$ and $60 \mathrm{~kg} / \mathrm{cm}^{2}$ in the ratio of $1.0: 0.85$, while Fig. 16 indicates similar changes with conventional amalgam, Shofu Micro Non-zinc Amalgam, under the same condensing conditions. Whereas there is almost no difference in the former, a large difference is found in the latter. Figs. 17,18 and 19 respectively relate to the cases of G-C Luna Amalgam, S. S. White New True Dentalloy and Caulk Micro Non-zinc Amalgam. Similar differences because of condensation pressures are noted as in Fig. 16.

A segment $a-m$ (Fig. 20) was measured as an indication of marginal fracture involved and it was also possible to measure the opposite fracture, $b-m$, as a horizontal surface by paying proper atten- 
tion to an angle of test specimen holder. (Fig. 14). Therefore, by linking three points $m, a$ and $b$ by a straight line, one can plot an angle of fracture corresponding to an angle $p-a-b$. When the vertical section of $a-b$ is actually observed, it is by no means a simple straight line as is learned from Figs. 21, 22, 23 and 24 which deal with spherical amalgam. While these figures represent different angles of $30^{\circ}, 45^{\circ}, 60^{\circ}$ and $90^{\circ}$, an examination of conventional amalgam gives more or less the identical sections at these angles. When a triangle $a-m-b$ formed by $a$ and $b$ is examined with regard to spherical, on the one hand, and conventional amalgam, on the other, it can be established that when a marginal angle is uniform, both of these will have nearly analogous patterns. But an interesting fact is noted that while with conventional amalgam the area of a triangle becomes smaller according as whether it is condensed under $10 \mathrm{~kg} / \mathrm{cm}^{2}$ or $60 \mathrm{~kg} / \mathrm{cm}^{2}$, with spherical amalgam the area of the same triangle remains nearly constant regardless of a change in condensation pressure. For instance, $10 \mathrm{~kg} / \mathrm{cm}^{2}$ condensation of Shofu spherical amalgam is compared with $60 \mathrm{~kg} / \mathrm{cm}^{2}$ condensation of Shofu Micro Non-zinc Amalgam in Fig. 25. As is evident from this, when an angle $p-a-b$ is measured by a divider both spherical

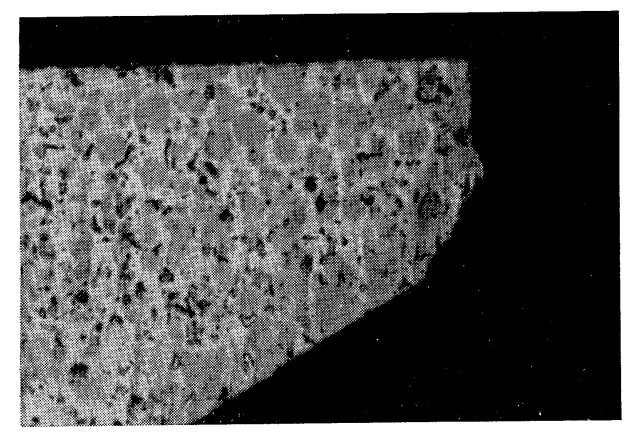

Fig. 21. A section of angle $30^{\circ}$

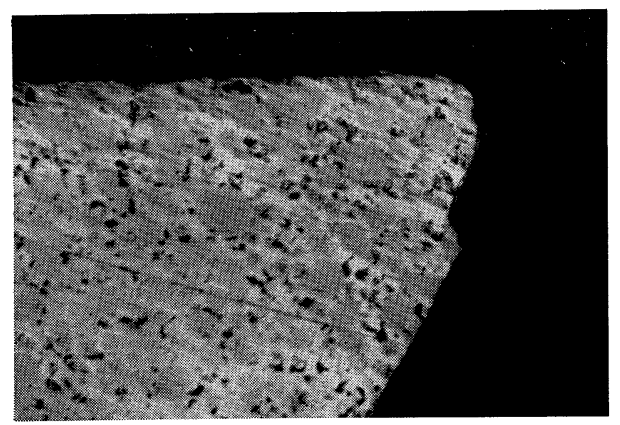

Fig. 23. A section of angle $60^{\circ}$

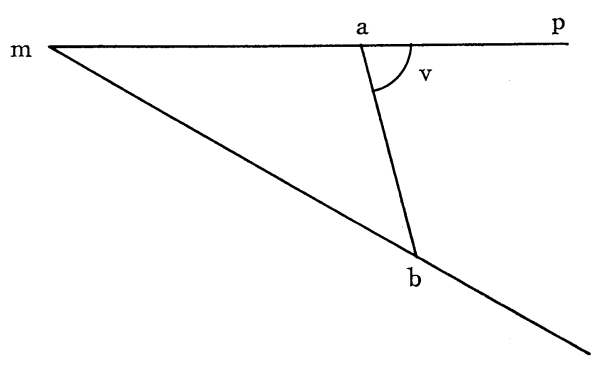

Fig. 20. Computation of the fracture angle (V)

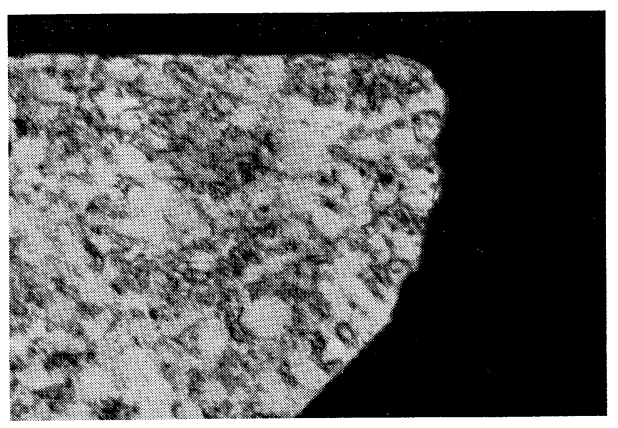

Fig. 22. A section of angle $45^{\circ}$

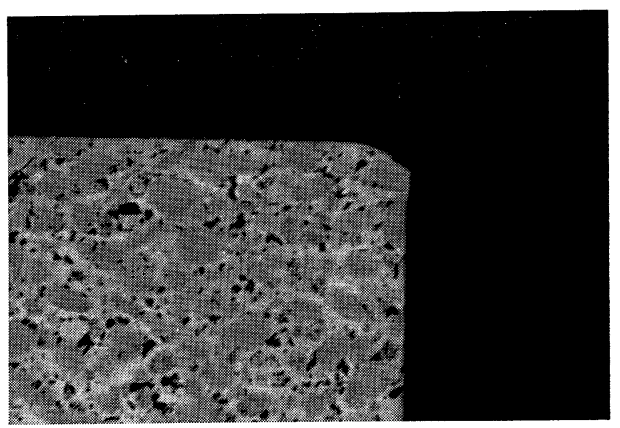

Fig. 24. A section of angle $90^{\circ}$ 
$\mathrm{S}$.

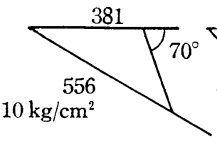

$30^{\circ}$

M. $60 \mathrm{~kg} / \mathrm{cm}^{2}$

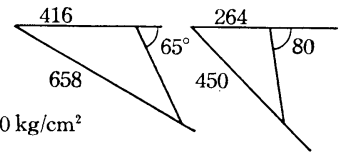

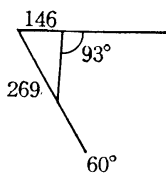
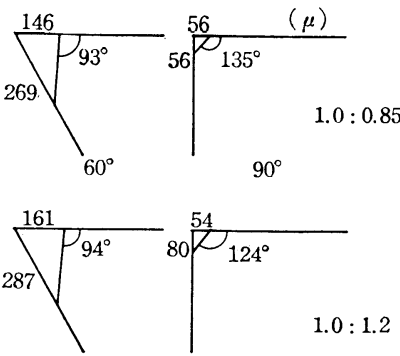

24 Hours

Fig. 25. Effect of marginal angle on depth of fracture of amalgam

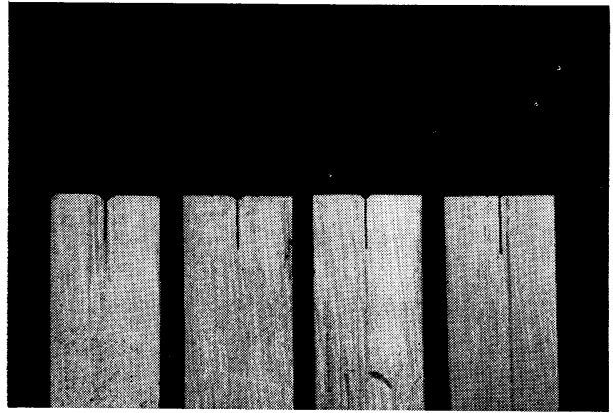

Fig. 26. Fractured test specimens $\left(30^{\circ}, 45^{\circ}, 60^{\circ}, 90^{\circ}\right.$ from 1 . to r. $)$ and conventional amalgams give more or less the same fracture angle provided that a marginal angle is constant. In both cases, when a marginal angle becomes larger, a marginal fracture will be correspondingly small having a large fracture angle in consequence. Fig. 26 shows outward appearances of these test specimens which developed the marginal fractures at various angles already referred to (reading $30^{\circ}, 45^{\circ}, 60^{\circ}$ and $90^{\circ}$ from left to right).

4.2 Changes in marginal strength to the time passage.

By way of experimental materials, test specimens were prepared from Shofu Spherical Amalgam, Shofu Micro Non-zinc Amalgam, G-C Luna Amalgam, S. S. White New True Dentalloy and Caulk Micro Non-zinc Amalgam in the same manner as in the preceding tests. These test specimens were so treated as to have a marginal angle of $30^{\circ}$. This particular angle was chosen from the fact that clinically an excessively filled amalgam tends to have an acute angle. Changes to the passage of time were investigated at intervals of $5,10,24$ hours and 7 days by keeping the test specimens at a constant temperature of $37^{\circ} \mathrm{C}$. The results are given in Table 5 . It is to be noted that the marginal strength of spherical amalgam is far greater than that of any of conventional amalgam tested. Fig. 27, which is concerned with an alloy-to-mercury ratio of $1.0: 0.85$ with a marginal angle of $30^{\circ}$, gives evidence to the fact that although the marginal strength increases till 10 hours after being triturated it becomes nearly flat afterward with no further change. This finding is in support of a conclusion that spherical amalgam completes its amalgamation in about 10 hours, the same tendency being true whether it is condensed under $10 \mathrm{~kg} / \mathrm{cm}^{2}$ or $60 \mathrm{~kg} / \mathrm{cm}^{2}$.

Figs. 28, 29 and 31, respectively concerned with Shofu Micro Non-zinc Amalgam, G. C. Luna Amalgum and Caulk Micro Non-zinc Amalgam, indicate a large difference between the two condensation pressures and the marginal strengths of these three products attain to almost the same maximum in about 10 hours.

On the other hand, Fig. 30 reveals that S S. White New True Dentalloy requires 
something like 24 hours to reach the maximum. Table 6 gives the amounts of residual mercury of amalgam products used for the present study. Since spherical amalgam can be triturated with less mercury to start with, its residual mercury is proportionally

TABLE 5

Effect of elapsed time on depth of fracture of various amalgams

Temp. $37^{\circ} \mathrm{C} \quad$ Angle $30^{\circ}$

\begin{tabular}{|c|c|c|c|c|c|}
\hline Name & $\begin{array}{l}\text { Shofu } \\
\text { Spherical }\end{array}$ & $\begin{array}{l}\text { Shofu } \\
\text { Micro }\end{array}$ & $\begin{array}{l}\text { G. C. } \\
\text { Luna }\end{array}$ & $\begin{array}{l}\text { S. S. White } \\
\text { New } \\
\text { True Dent. }\end{array}$ & $\begin{array}{l}\text { Caulk } \\
\text { Micro }\end{array}$ \\
\hline Ratio & $1.0: 0.85$ & $1.0: 1.2$ & $1.0: 1.2$ & $1.0: 1.2$ & $1.0: 1.2$ \\
\hline Time $\mathrm{kg} / \mathrm{cm}^{2}$ & $10 \quad 60$ & $10 \quad 60$ & $10 \quad 60$ & $10 \quad 60$ & 10 \\
\hline 5 Hours & $\begin{array}{l}531 \mu 503 \mu \\
(28) \quad(28)\end{array}$ & $\begin{array}{l}639 \mu 540 \mu \\
(56)(106)\end{array}$ & $\begin{array}{l}600 \mu 524 \mu \\
(14) \quad(82)\end{array}$ & $\begin{array}{l}582 \mu 578 \mu \\
(36) \quad(37)\end{array}$ & $\begin{array}{l}650 \mu 556 \mu \\
(46) \quad(35)\end{array}$ \\
\hline 10 Hours & $\begin{array}{ll}386 & 375 \\
(30) & (22)\end{array}$ & $\begin{array}{ll}518 & 446 \\
(40) & (27)\end{array}$ & $\begin{array}{ll}459 & 432 \\
(32) & (6)\end{array}$ & $\begin{array}{ll}546 & 516 \\
(41) & (37)\end{array}$ & $\begin{array}{ll}507 & 434 \\
(66) & (14)\end{array}$ \\
\hline 24 Hours & $\begin{array}{ll}381 & 374 \\
(39) & (10)\end{array}$ & $\begin{array}{ll}447 & 416 \\
(46) & (31)\end{array}$ & $\begin{array}{ll}417 & 411 \\
(13) & (8)\end{array}$ & $\begin{array}{ll}417 & 381 \\
(22) & (27)\end{array}$ & $\begin{array}{cc}443 & 413 \\
(21) & (10)\end{array}$ \\
\hline 7 days & $\begin{array}{ll}370 & 362 \\
(12) & (18)\end{array}$ & $\begin{array}{ll}414 & 405 \\
(35) & (37)\end{array}$ & $\begin{array}{ll}402 & 399 \\
(21) & (25)\end{array}$ & $\begin{array}{ll}404 & 366 \\
(45) & (31)\end{array}$ & $\begin{array}{rr}411 & 402 \\
(20) & (8)\end{array}$ \\
\hline
\end{tabular}

Numbers in parentheses are standard deviation.

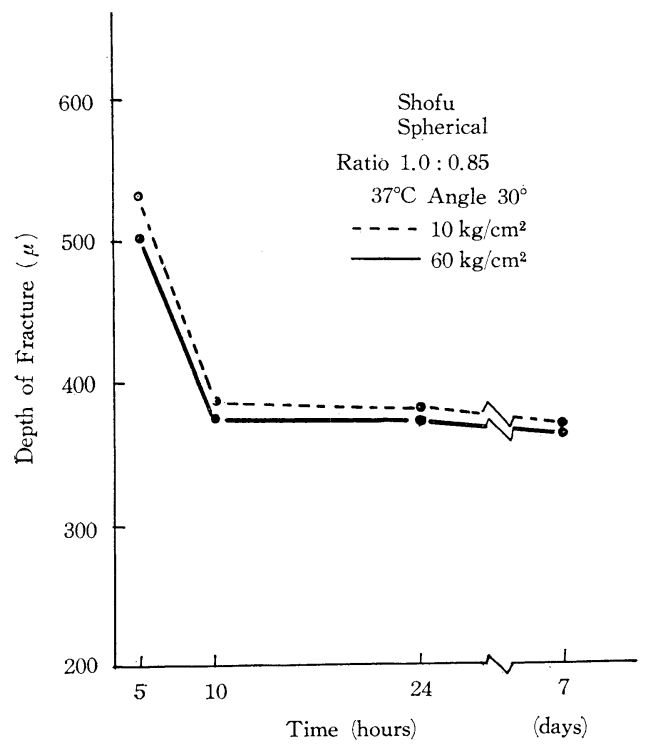

Fig. 27. Effect of elapsed time on depth of fracture of amalgam

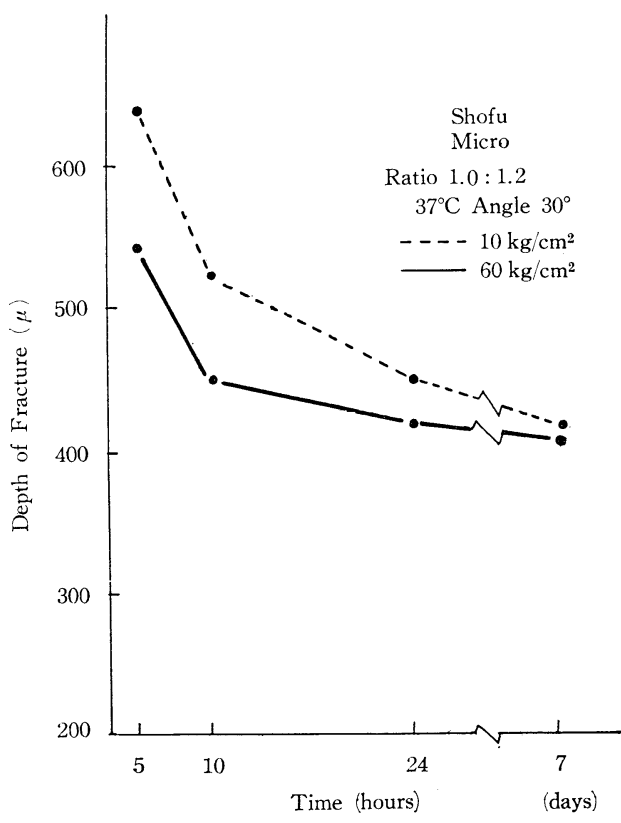

Fig. 28. Effect of elapsed time on depth of fracture of amalgam 
small. When compared with 4 different conventional amalgam products under $60 \mathrm{~kg} / \mathrm{cm}^{2}$, spherical amalgam which is packed under $10 \mathrm{~kg} / \mathrm{cm}^{2}$ has much less residual mercury.

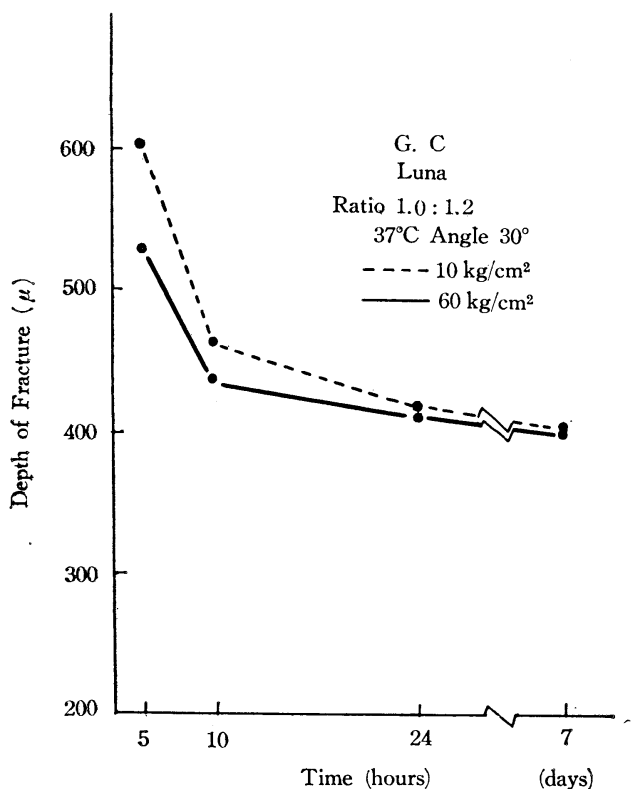

Fig. 29. Effect of elapsed time on depth of fracture of amalgam

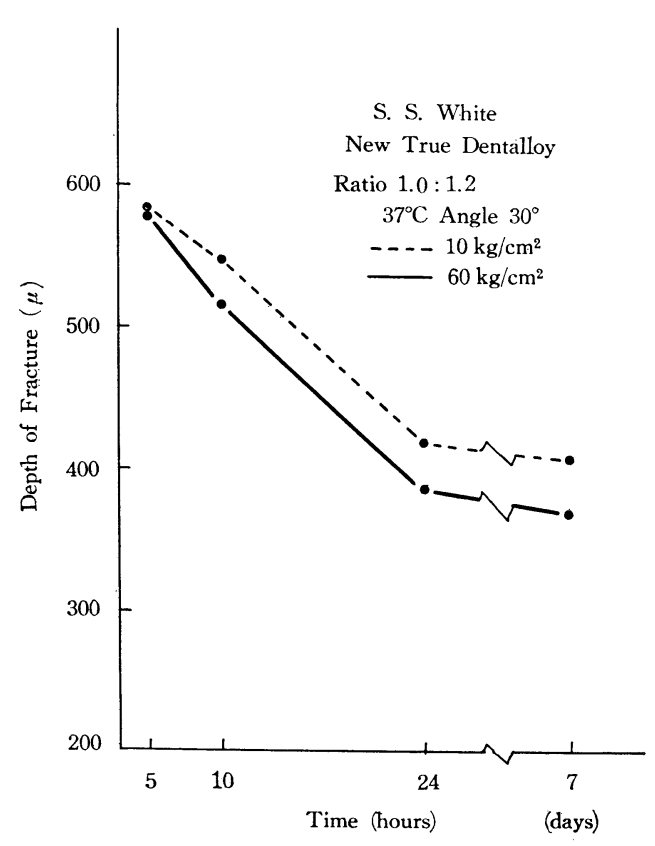

Fig. 30. Effect of elapsed time on depth of fracture of amalgam

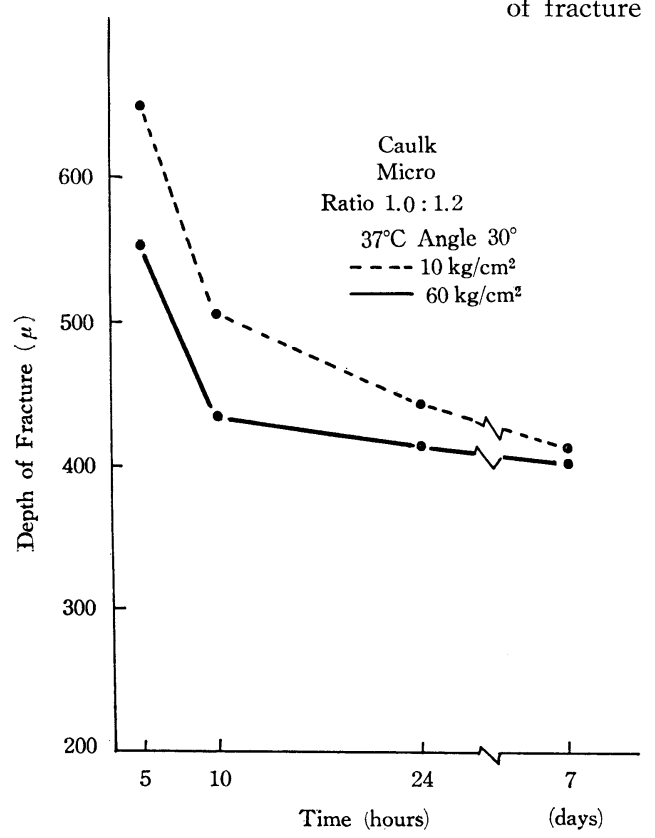

Fig. 31. Effect of elapsed time on depth of fracture of amalgam 
TABLE 6

Residual mercury

\begin{tabular}{c|c|c|c|c|c}
\hline & $\begin{array}{c}\text { Shofu } \\
\text { Spherical }\end{array}$ & $\begin{array}{c}\text { Shofu } \\
\text { Micro }\end{array}$ & $\begin{array}{c}\text { G. C. } \\
\text { Luna }\end{array}$ & $\begin{array}{c}\text { S. S. White } \\
\text { New } \\
\text { True Dent }\end{array}$ & $\begin{array}{c}\text { Caulk } \\
\text { Micro }\end{array}$ \\
\hline$\%$ & $\%$ & $\%$ & $\%$ & $\%$ \\
\hline $60 \mathrm{~kg} / \mathrm{cm}^{2}$ & 44 & 49 & 49 & 49 & 47 \\
\hline $10 \mathrm{~kg} / \mathrm{cm}^{2}$ & 46 & 53 & 52 & 51 & 51 \\
\hline Ratio & $1.0: 0.85$ & $1.0: 1.2$ & $1.0: 1.2$ & $1.0: 1.2$ & $1.0: 1.2$
\end{tabular}

For this reason, spherical amalgam is found far advantageous in respect of residual mercury.

\section{Discussions}

\subsection{Consideration of experimental method.}

As a comparative method with the marginal strength of amalgam, the compressive strength is generally measured as its indirect indication. However, although the preparation of test specimens for the compressive strength study is fairly easy and its experimental data possess a high degree of reliability, it is questionable whether the compressive strength can be directly utilized as indicative of the marginal strength of amalgam concerned [19]. That is to say, an amalgam filling under clinical conditions is by no means a simple cylindar form but it tends to assume a complex morphology and, in this connection, we should not lose sight of the fact that even if an external force which acts on the filling at the mastication is chiefly a compressive load, there are also effects of shearing and tensile stresses at work. It was from these considerations that J $\phi$ RGENSEN of Denmark and his associates [18] developed a method of scratch. ing test that is capable of quantitatively expressing the marginal strength of amalgam in terms of the length of fractured portion.

Since it is generally maintained that the degree of marginal strength is in proportion to the area of fractured portion of amalgam filling, one method of determining its marginal strength would be to measure the cubic volume; however, this method would be rather complicated in actual practice. As is noted from Fig. 25, the larger is a marginal angle the smaller will be the length of fracture proportionally and, therefore, the area of $a-m-b$ (reference is already made to Fig. 20) tends to become small and the marginal strength increases.

An easier method for the measurement of the degree of marginal strength is to make use of the fact that when a marginal angle is the same, a triangle thus formed is nearly analogous regardless of the kind of amalgam whether it is spherical or conventional.

In keeping with this thinking, the authors examined a method proposed by $\mathrm{J} \phi \mathrm{R}$ GENSEN and introduced such new features as the conjoint use of Micro Vickers hardness tester, special holder for the retention of test specimens and uniform distance of dropping a steel ball on specimens, thus making it possible for the minute measurement of marginal strength of amalgam. It is to be emphasized that, as compared with 
J $\phi$ RGENSEN's method, our method employed in the present study is easier in respect of both the measurement and microscopic examination of fractured portion of amalgam fillings and, therefore, it is possible to obtain more accurate measurement data far readily.

\subsection{Consideration of experimental results.}

\subsubsection{Influences of angles on marginal strength.}

When various marginal angles ranging from $30^{\circ}$ to $90^{\circ}$ were compared one with another, the tendency was observed in common with all the amalgam specimens, spherical and conventional alike, that the larger was a marginal angle the degree of marginal fracture was small with a proportionally increased marginal strength.

J $\phi$ RGENSEN [18] studied the marginal strength of one conventional amalgam product packed under one condensation pressure and his findings are more or less in line with these results. Although the marginal strength of spherical amalgam was greater than any of conventional amalgam specimens here under study, it increased according as marginal angle became large and at $90^{\circ}$ there was almost no difference between spherical and conventional amalgams. On the other hand, while spherical amalgam is hardly influenced by a condensation pressure involved, conventional amalgam is otherwise as has been already reported.

When conventional amalgam specimen packed under $10 \mathrm{~kg} / \mathrm{cm}^{2}$ was compared with that of $60 \mathrm{~kg} / \mathrm{cm}^{2}$ pressure, there was definitely observed a difference between their marginal strengths, much reduction being apparent in the former.

This can be explained by the fact that with spherical amalgam a small condensation pressure is sufficient to produce a compactly packed filling by reason of its particles being spherical. It has been also substantiated by a result of our study of its compressive strength [14].

In this connection, our finding that when a marginal angle is large it results in a correspondingly large fracture angle with an increased marginal strength provides a theoretical basis for a general clinical principle which dictates that an amalgam filling should be given an angle as large as possible.

\subsubsection{Changes in marginal strength to the time passage.}

As already referred to in Table 5 and Fig. 27, the marginal strength of spherical amalgam reaches its maximum in about 10 hours. As regards conventional amalgam, three products of Shofu, G-C and Caulk took the same length of time for their marginal strengths to reach a maximum but with a S. S. White product 24 hours were necessary to reach the same effect.

As has been stated elsewhere, one advantage of spherical amalgam is sought in the fact that it is hardly influenced by an amount condensation pressure. On the other hand, a clear difference was apparent between conventional amalgam specimen packed under $10 \mathrm{~kg} / \mathrm{cm}^{2}$ and that packed under $60 \mathrm{~kg} / \mathrm{cm}^{2}$. This serves as a confirmation of the foregoing statement that a difference in condensation pressures is not meaningful with spherical amalgam. After all, a high degree of clinical advantage is offered by spherical amalgam as it reaches a maximum of its marginal strength in a relatively short period of time. 


\section{Conclusions}

The present study was concerned with the measurements of spherical amalgam newly developed in Japan together with 4 conventional amalgams (2 demestic and 2 foreign products) with reference to their respective marginal strengths. As a result, the authors obtained the following conclusions.

1. A conventional Micro Vickers hardness tester was modified to suit our purpose of measuring the marginal strength of amalgam specimens. This modified apparatus was proved to obtain satisfactory results.

2. When a marginal angle happens to be the same, a resultant angle of fracture will be no different from conventional to spherical amalgams. But, even so, the length of fractured portion will differ and, consequently, there will be difference in the marginal strength. Generally speaking, spherical amalgam has a stronger marginal strength than conventional amalgam.

3. A marginal angle is in direct proportion to that of fracture. Marginal strength of amalgam increases correspondingly. In common to various angles, spherical amalgam has a stronger marginal strength than conventional amalgam.

4. As compared with conventional amalgam, spherical amalgam has a larger marginal strength in the passage of time. Moreover, chief characteristic of spherical amalgam consists in the fact that it attain to a maximum marginal strength within 10 hours from the start of trituration and there is no appreciable change from this time on.

5. Although marginal strength of spherical amalgam is not influenced by a condensation pressure to any appreciable extent, that of conventional amalgam is influenced to a pronounced degree proportionally.

\section{References}

[1] American Dental Association, Bureau of Economic Research and Statistics, 1959 Survey of Dental Practice, J. A. D. A., 62: 627, 1961.

[2] Healey, H. J. and Phillips, R. W. : Clinical Study of Amalgam Failure, J. Dent. Res, 28 : 439, 1949.

[3] SeIno, S. : Clinical Observation on the Amalgam Filling in School Children as an Early Precaution against the Dental Caries, J. Japan Research Soc. Dent. Mat. and Appl., No. $15,1966$.

[4] Fusayama, T., Wakumoto, S., Katayori, T., Kono, A., Shimizu, M., Hanari, M. and Hayashi, K. : Clinical Results of Amalgam Fillings, J. Japan Research Soc. Dent. Mat. and Appl., 8 : 79, 1962.

[5] SAijo, M. : On the Prognosis of Amalgam Fillings, Shikai-Tembo, 15: 794, 1958.

[6] Habu, H., Henmi, I. and Kunil, H. : Failures in Amalgam Restoration, J. Japan Research Soc. Dent. Mat. and Appl., 6 : 32, 1961.

[7] Wilson, C. J. and Ryge, G. : Clinical Study of Dental Amalgam, J. A. D. A., 66 : 763, 1963.

[8] Probst, R. L., Karp, P. I., Sayer, C. H. and Beebe, A. H. Jr. : Assignors to FederalMogul-Bower Bearings, Inc., Detroit, Michigan, Atomizing Nozzle and Pouring Cap Assembly for the Manufacture of Metal Powders, US Patent No. 2,968,062, January 17, 1961.

[9] Demaree, N. C. and TAylor, D. F. : Properties of Dental Amalgams made from Spherical Alloy Particles, J. Dent. Res., 41 : 890, 1962.

[10] Koran, A. and Asgar, K. : Usage of Spherical Amalgam Alloy in Dentistry, presented at the I. A. D. R. annual meeting for 1965.

[11] Eden, G. T. and Waterstrat, R. M. : Effect of Packing Pressure on Tensile Strength 
of Commercial and Spherical Dental Amalgams, presented at the I. A. D. R. annual meeting for 1965 .

[12] Wing, G. and Ryge, G. : Setting Reactions of Spherical-particle Amalgams, J. Dent. Res., 4 : 1325, 1965.

[13] Kamata, T. : Properties of Dental Silver-tin Amalgam made from Atomized Alloy Particles and the Effect of Heat Treatment of Alloy Particles, J. Japan Soc. Dent. Appa. and Mat., 6: 80, 1965.

[14] Nagai, K., Ohashi, M. and Mryazu, H. : Studies on Spherical Amalgam Alloy in the Light of Dental Technology, J. Nihon Univ. Sch. Dent., 8: 149, 1966.

[15] Nagai, K. and OHashi, M. : Studies on the Dimensional Change of Dental Amalgams, J. Nihon Univ. Sch. Dent., 9 : 1, 1967.

[16] NAGAi, and Ohashi, M. : Three Studies on a Newly Developed Spherical Amalgam in Japan and Suggestions for its Specification, J. Nihon Univ. Sch. Dent., 9 : 2, 1, 1967.

[17] J $\phi$ Rgensen, K. D. : The Mechanism of Marginal Fracture of Amalgam Fillings, Acta Odont. Scand., 23 : 347, 1965.

[18] J $\phi$ Rgensen, K. D. and PAlB $\phi$ L, O. P.: Experiments on the Relationship between the Strength and the Angle of Amalgam Margins, Acta Odont. Scand., 23 : 513, 1965.

[19] Skinner, E. W. and Phillif', R. W. : The Science of Dental Materials, W. B. Saunders Company, Philadelphia, 5th ed., 1960. 